\title{
Molecular characterization and potential sources of aqueous humor bacterial contamination during phacoemulsification with intraocular lens implantation in dogs
}

\author{
Luciana C.C. Lacerda ${ }^{\mathrm{a}}$, Andressa de Souza-Pollo ${ }^{\mathrm{b}}$, Ivan Ricardo M. Padua ${ }^{\mathrm{a}}$, Luciano F. Conceição ${ }^{\mathrm{a}}$, \\ Camila P. Balthazar da Silveira ${ }^{a}$, Germana A. Silva ${ }^{a}$, Renato P. Maluta ${ }^{c}$, José L. Laus ${ }^{\mathrm{a}, *}$ \\ ${ }^{a}$ Department of Veterinary Clinic and Surgery, São Paulo State University-FCAV/UNESP, Jaboticabal, São Paulo, Brazil \\ ${ }^{\mathrm{b}}$ Laboratory of Molecular Epidemiology, Department of Preventive Veterinary Medicine and Animal Reproduction, São Paulo State University-FCAV/UNESP, Jaboticabal, \\ São Paulo, Brazil \\ ${ }^{\mathrm{c}}$ Department of Genetics, Evolution and Bioagents, Institute of Biology, University of Campinas-UNICAMP, Campinas, São Paulo, Brazil
}

\section{A R T I C L E I N F O}

\section{Keywords:}

Cataract

16S rRNA sequencing

Anterior chamber

Conjunctival surface

rep-PCR

Dog

\begin{abstract}
A B S T R A C T
Bacterial contamination of the anterior chamber during cataract surgery is one of the main responsible for endophthalmitis postoperative. Phacoemulsification is a less invasive technique for cataract treatment, although it does not exclude the possibility of contamination. In this study, bacterial contaminants of aqueous humor collected pre- and post-phacoemulsification with intraocular lens implantation (IOL) of twenty dogs were identified. As the conjunctival microbiota constitute a significant source of anterior chamber contamination, bacterial isolates from aqueous humor were genetically compared with those present in the conjunctival surface of the patients. Three dogs presented bacterial growth in both aqueous humor and conjunctival surface samples. Bacterial isolates from these samples were grouped according to their genetic profiles by repetitive-element PCR (rep-PCR) and their representatives were identified by 16S rRNA sequencing. Isolates from conjunctival surface were identified as Enterobacter spp., Staphylococcus spp. and S. aureus; and from aqueous humor samples as Enterobacter spp., Pantoea spp., Streptococcus spp. and Staphylococcus spp., respectively in decreasing order of prevalence. According to the rep-PCR analysis, 16.6\% of Enterobacter spp. isolates from conjunctival surface were genetically similar to those from aqueous humor. The rest of isolates encountered in aqueous humor were genetically distinct from those of conjunctival surface. The significant genetic diversity of bacterial isolates found in the aqueous humor samples after surgery denoted the possibility of anterior chamber contamination during phacoemulsification by bacteria not only from conjunctival surface but also from different sources related to surgical environment.
\end{abstract}

\section{Introduction}

Phacoemulsification is the current technique of choice for cataract surgery in dogs. This method of surgery requires a small incision and enhances the safety of IOL implantation with minimal chances of postoperative complications (Gilger, 1997). Endophthalmitis after phacoemulsification is rare, around $0.4 \%$ (Johnstone and Ward, 2005) of the cases in dogs. However, bacterial contamination of the anterior chamber may occur with relative high frequency, ranging from $9 \%$ to $31 \%$ of the surgeries (Taylor et al., 1995; Ledbetter et al., 2004).

Conjunctival surface is considered the main source of contamination of the anterior chamber (Ariyasu et al., 1993). Conjunctival fluid has been shown to flow into the anterior chamber during the extracapsular lens extraction aspiration stage and IOL implantation (Sherwood et al.,
1989). Other factors should be considered as contributors for anterior chamber contamination, as operating solutions, instruments, operating room and surgeon (Taylor et al., 1995).

Conjunctival bacterial microbiota encompasses resident and opportunistic microorganisms. The residents often inhibit the growth of pathogens through nutritional competition and secretion of active substances. This dynamic plays an important role in the ocular protection against infections. Nevertheless, infectious disease or persistent use of antibiotics and/or corticosteroids can harm the resident microbiota and allow the multiplication of opportunistic pathogens with the consequent establishment of the disease (Gerding and Kakoma, 1990). A previous study has demonstrated that microorganisms present in the anterior chamber of dogs' eyes after phacoemulsification were similar to those detected in conjunctival surface by bacteriological culture and

* Corresponding author. 


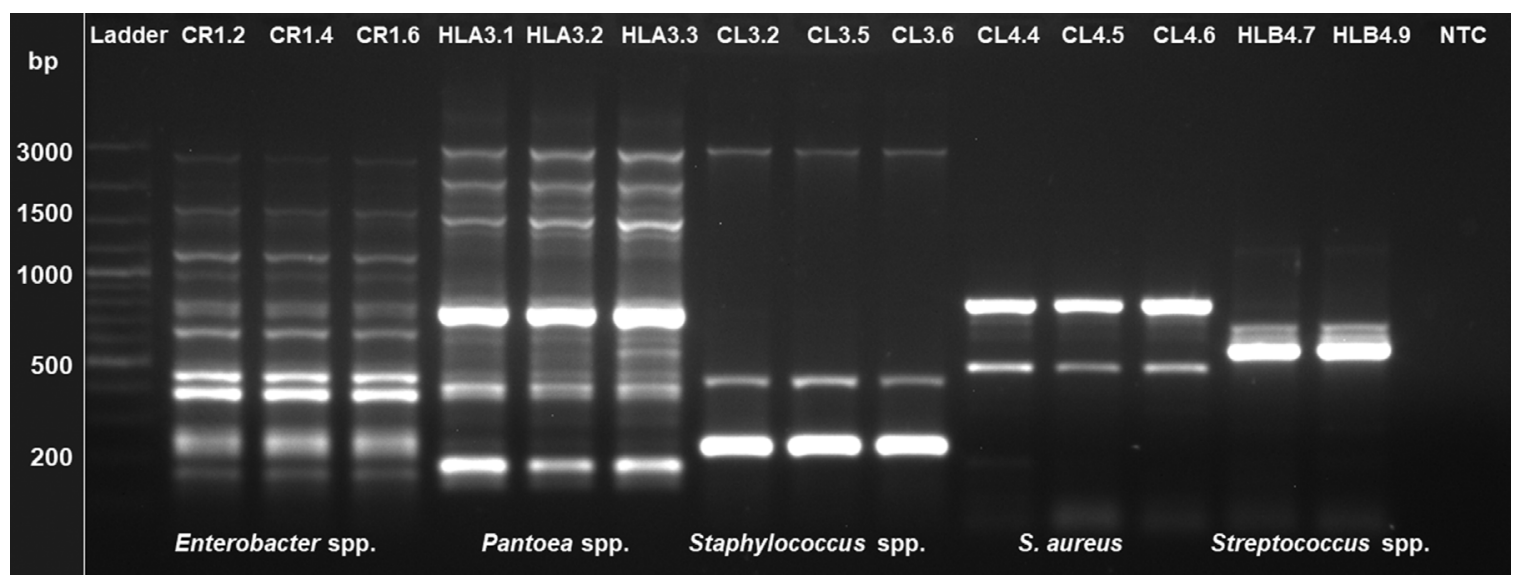

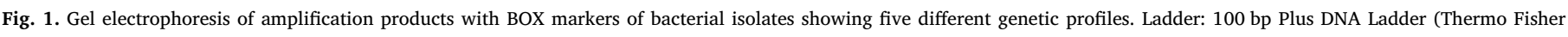
Scientific). NTC: no template control.

antimicrobial susceptibility (Ledbetter et al., 2004).

A currently recommendable approach for detection of bacterial contamination sources and species related to infectious diseases of eyes is by associating traditional culture methods with molecular techniques (Sharma, 2012). The sequencing of 16S rRNA has been successfully applied for bacterial genus classification (Mizrahi-Man et al., 2013; Srinivasan et al., 2015), while molecular markers such as repetitiveelement PCR (rep-PCR) has been aiding the classification of bacterial isolates by genomic fingerprint patterns (Agostinho et al., 2014; Li et al., 2017).

Owing to bring up to date the researches comprising bacterial contamination of anterior chamber after phacoemulsification of dogs, this study aimed to identify bacterial contaminants of aqueous humor of dogs during the surgery with intraocular lens implantation by molecular approaches and genetically correlate them with those present in the conjunctival surface.

\section{Methods, techniques}

\subsection{Patients}

A total of 20 non-diabetic dogs of different breeds, affected by bilateral immature or mature cataracts were sampled. The dogs did not show systemic or ophthalmic diseases and sequelae of ocular inflammation, except for the cataracts.

\subsection{Preoperative therapy}

One hour before surgery, the dogs received one drop of topical combination of dexamethasone and tobramycin (Tobradex, Alcon Labs, São Paulo, Brazil). In addition, one drop of $1 \%$ atropine sulfate (Atropine Eye Drops, Allergan, São Paulo, Brazil) were applied after $30 \mathrm{~min}$.

\subsection{Antisepsis and phacoemulsification}

Pre-anesthetic medication was delivered by intramuscular injection of a combination of meperidine $(4 \mathrm{mg} / \mathrm{kg}$ ) (Fentanest, Cristália, Itapira, Brazil) and diazepam $(0.3 \mathrm{mg} / \mathrm{kg}$ ) (Diazepam, Hipolab, Eymard, Brazil). General anesthesia was induced with propofol $(5 \mathrm{mg} / \mathrm{kg})$ (Propovan, Cristália, Itapira, Brazil) and maintained with isoflurane (Isothane, Baxter, Guayama, Puerto Rico). The dogs were positioned in dorsal decubitus and the eyelids and periocular hair area were clipped closely. Both eyes were submitted to antisepsis. About $5.0 \mathrm{~mL}$ of $10 \%$ iodopyrrolidine aqueous solution was used on the eyelids and periocular skin, while the ocular surface and eyelid margins were flushed with the same volume of the $0.9 \%$ iodopyrrolidine. All these procedures were repeated three times immediately before the surgery.

The surgical technique adopted was bimanual phacoemulsification, one principal and one auxiliary, both located in the clear cornea approximately $1.0 \mathrm{~mm}$ from the limbus. A capsule dye (Trypan Blue, Ophthalmos, São Paulo, Brazil) was injected into the anterior chamber. A mixture of viscoelastic solutions, composed of $4 \%$ chondroitin sulfate, $3 \%$ sodium hyaluronate and $1 \%$ sodium hyaluronate (Duovisc, Alcon Labs, São Paulo, Brazil) were then injected in the anterior chamber. The anterior capsular incision was made with a cystotome, followed by continuous curvilinear capsulorhexis with an Utrata forceps, and hydrodissection of the nucleus was performed. The technique used was 'divide and conquer' nucleofraction phacoemulsification. The cortex was removed by irrigation and aspiration. A foldable acrylic IOL (30-V 12.0/30 V-14.0 - Acrivet, Hennigsdorf, Germany) was implanted in the capsular bag. The clear corneal incision was sutured by 9-0 Polyglactin 910 (Vicryl, Ethicon, São Paulo, Brazil) in a simple interrupted pattern.

\subsection{Sampling}

Following the induction of general anesthesia, samples were collected after clipping the hair of surgical area and antisepsis of the conjunctival sacs. Samples of conjunctival surface from both eyes were collected using sterile swabs as described on literature (Ledbetter et al., 2004; Sharma, 2012). Swabs were gently passed by the dorsal and ventral conjunctival fornix and by the superior and inferior eyelid margins. Contact with palpebral skin and eyelashes were avoided. Immediately after samples collection, the swabs were placed in tubes containing Brain Heart Infusion broth (BHI). At the beginning of surgery, immediately after anterior chamber entry, and at the end of surgery, immediately before the corneal suture, aliquots of $0.5 \mathrm{~mL}$ of aqueous humor were collected from both eyes through corneal groove with a $1 \mathrm{~mL}$ sterile syringe.

Conjunctival and aqueous humor samples were transported to the Molecular Epidemiology Laboratory on ice, where the samples were manipulated in an aseptic chamber. Each conjunctival surface sample and aqueous humor aliquot was divided and placed into two tubes containing BHI broth, being one maintained in aerobiosis and the another in anaerobiosis, in hermetic jars with Anaerobac System (Probac, Sao Paulo, Brazil). The tubes were incubated at $37^{\circ} \mathrm{C}$ for 18 to $48 \mathrm{~h}$.

\subsection{Postoperative therapy}

Prednisone (Prednisona, Medley, Campinas, Brazil) was administered orally $(1 \mathrm{mg} / \mathrm{kg})$ at $24 \mathrm{~h}$ intervals for 15 consecutive days, followed by gradual reduction of the dose over the following 15 days. First, one drop of dexamethasone associated with tobramycin 


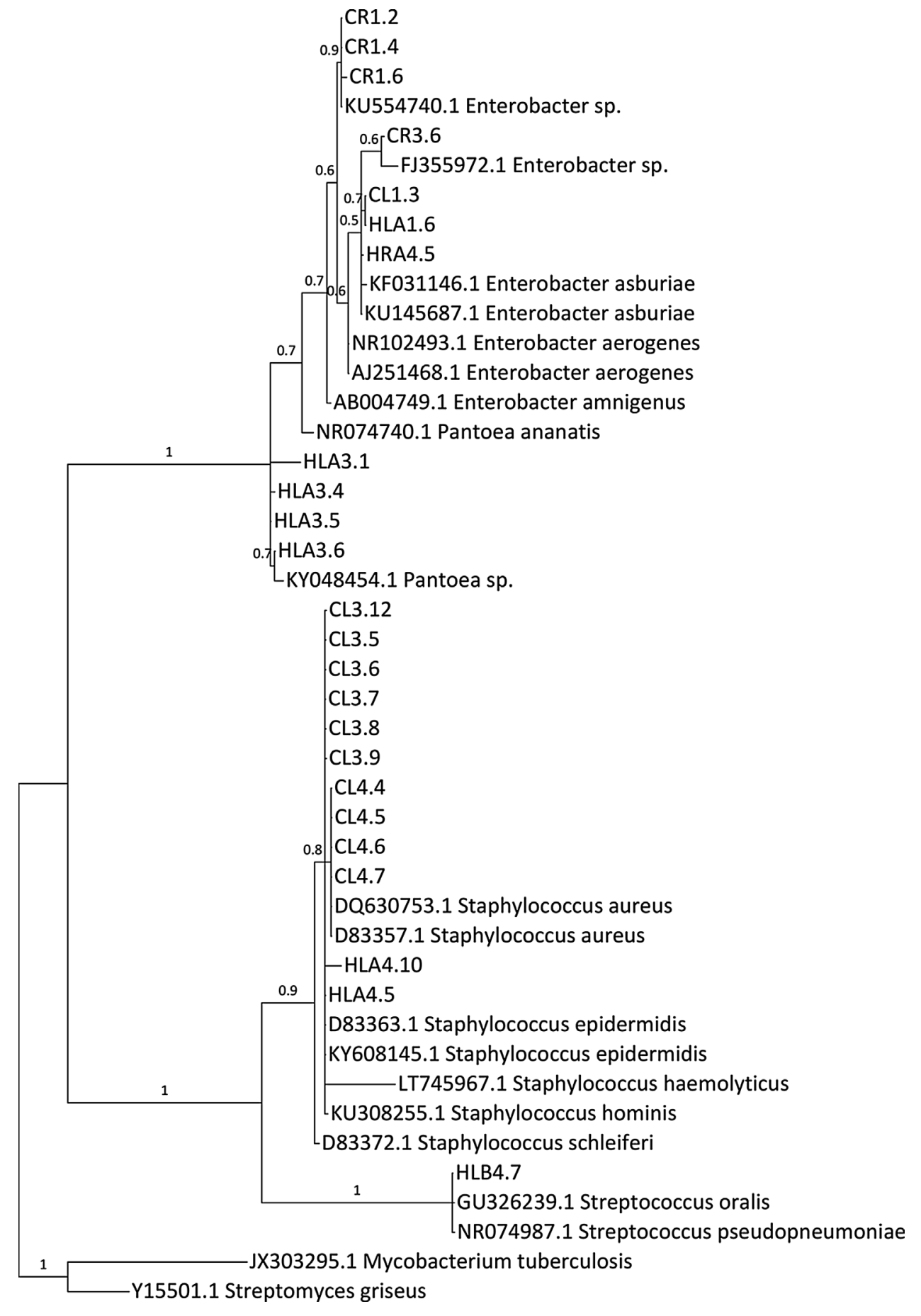

Fig. 2. Bayesian analysis of $16 \mathrm{~S}$ rRNA region of the representative bacterial isolates obtained from conjunctival surface and aqueous humor samples of dogs submitted to phacoemulsification.

Table 1

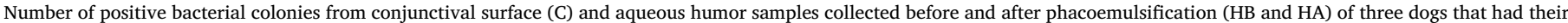
anterior chamber contaminated during the surgery.

\begin{tabular}{|c|c|c|c|c|c|}
\hline \multirow[t]{2}{*}{ Samples } & \multicolumn{5}{|c|}{ Number of isolates (\%) } \\
\hline & Enterobacter spp. & Pantoea spp. & Staphylococcus spp. & Staphylococcus aureus & Streptococcus spp \\
\hline $1 \mathrm{C}$ & $11(13.8 \%)$ & - & - & - & - \\
\hline $1 \mathrm{HA}$ & $5(6.2 \%)$ & - & - & - & - \\
\hline $3 C$ & $8(10 \%)$ & - & $11(13.8 \%)$ & - & - \\
\hline 3HA & - & $14(17.5 \%)$ & - & - & - \\
\hline $4 \mathrm{C}$ & $5(6.2 \%)$ & - & - & $4(5 \%)$ & $7(8.7 \%)$ \\
\hline $4 \mathrm{HB}$ & - & - & - & - & \\
\hline $4 \mathrm{HA}$ & $13(16.3 \%)$ & - & $2(2.5 \%)$ & - & - \\
\hline
\end{tabular}




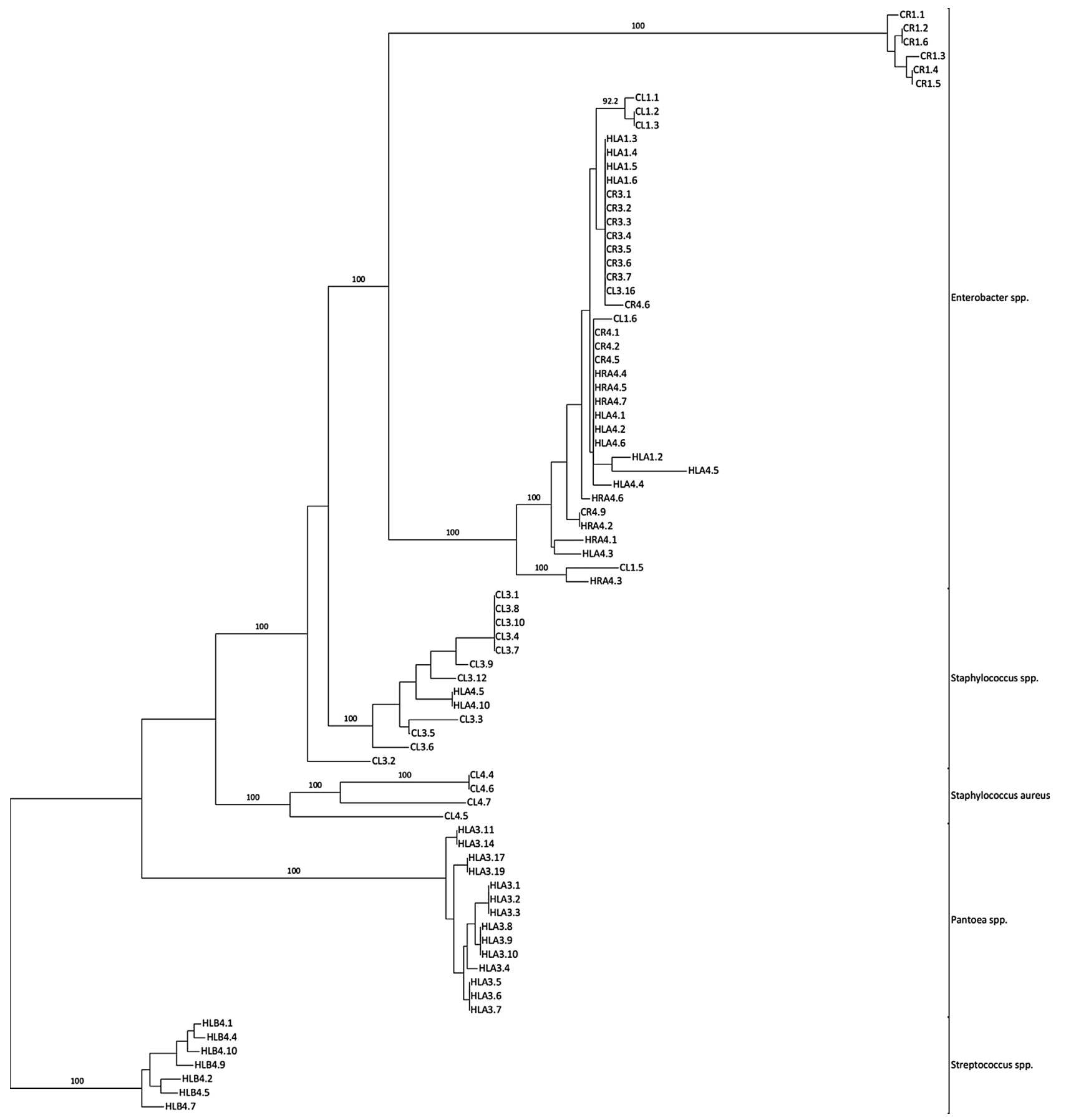

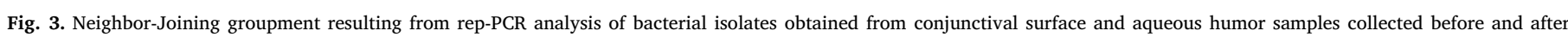
phacoemulsification surgery of dogs.

(Tobradex, Alcon Labs, São Paulo, Brazil) were applied six times a day for seven days and, after this period, four times a day for a minimum of 21 days. Diclofenac QID for 30 days, 1\% brinzolamide BID for 7 days, and atropine BID for 3 days were also administered to the eyes submitted to surgery.

\subsection{Bacterial isolation}

Both conjunctival surface and aqueous humor samples from the same patient showing bacterial growth in BHI broth were submitted to isolation in Blood Agar plates (Laborclin, Pinhais, Brazil), aerobically and anaerobically, at $37^{\circ} \mathrm{C}$ for $12 \mathrm{~h}$. All colonies types, at least ten colonies per sample, were picked and placed in tubes containing BHI broth that were incubated at the same conditions.

The isolates were identified according to their sources as follow: conjunctival surface samples of the right and left eyes (CR and CL); aqueous humor samples of the right and left eyes collected at the beginning of surgery (HRB and HLB); and aqueous humor samples of the right and left eyes collected after surgery (HRA and HLA). The code of samples was complemented with the number of the patient, from one to twenty, and subsequently, with the number of bacterial strain obtained.

\subsection{Molecular analysis}

\subsubsection{Screening of isolates}

All isolates obtained in Blood Agar were submitted to DNA 
extraction as proposed by Bag et al. (2016) in order to obtain DNA with high integrity. Owing to the large number of isolates obtained, those with different genetic profiles were selected, aiming to analyze as many diverse bacterial strains as possible. Tests with different primers that amplify repetitive regions (Versalovic et al., 1994; Koeuth et al., 1995) have been done, which allowed the selection of the primers that presented lower polymorphism, a valid characteristic for bacterial isolates screening using genetic profile. Thus, prior sequencing and rep-PCR genetic diversity analysis, all isolates obtained were submitted to screening with the set of primers BOXA1 and BOXC1R (Koeuth et al., 1995).

\subsubsection{S rRNA sequencing}

All isolates with different profiles according to the BOX-PCR were submitted to sequencing of $16 \mathrm{~S}$ rRNA region by applying the set of primers 8F/907R (Nercessian et al., 2005). The amplicons were partially sequenced by using Big Dye Terminator v3.1 Kit (Applied Biosystems, Waltham, USA) in an ABI 3100 Sequencer (Applied Biosystems, Waltham, USA). Even with absence of amplification product, negative controls of each reaction were submitted to sequencing to ensure the accuracy of data. Sequences were analyzed and trimmed by using the software package Phred/Phrap/Consed (Green, 1996; Ewing and Green, 1998; Gordon et al., 1998). Sequences from the GenBank and those obtained in this study were aligned by MUSCLE version 3.6 (Edgar, 2004). The best model for phylogenetic analysis was selected according to the Akaike Information Criterion (AIC) (Posada and Buckley, 2004). Phylogenetic analysis was then carried out in the MrBayes 3.2.3 software (Ronquist and Huelsenbeck, 2003) using four independent MCMC runs with ten million generations, with sampling every 200 generations. The initial $25 \%$ of trees were discarded in order to eliminate bias of the beginning of the analyzes.

The isolates identified by sequencing became the standards of the bacterial profiles obtained by BOX markers. Therefore, the isolates that presented the same profile of those sequenced were classified as well.

\subsection{3. rep-PCR}

The sequenced isolates and other representatives of the same genetic profile were submitted to the complete rep-PCR analysis for genetic diversity study of the population. Three set of primers were used, Rep1R-I associated with Rep2-I (Versalovic et al., 1994), Eric2 (Versalovic et al., 1994) and BoxC1R (Koeuth et al., 1995). PCR was performed using $1 \times$ buffer (20 mM Tris-HCl pH 8,4; $50 \mathrm{mM} \mathrm{KCl}$ ), $2,5 \mathrm{mM} \mathrm{MgCl}_{2}, 0.2 \mathrm{mM}$ dNTPs, $1.0 \mathrm{U}$ Taq DNA polymerase, 5 pmol of each primer, $60 \mathrm{ng}$ of genomic DNA and pure water to $20 \mu \mathrm{L}$ of solution. All reactions were prepared including a negative control, without template. Amplification was conducted in a thermocycler (Veriti Thermal Cycler, Applied Biosystems, Waltham, USA) programmed for one cycle at $95{ }^{\circ} \mathrm{C}$ for $4 \mathrm{~min} ; 36$ cycles at $94^{\circ} \mathrm{C}$ for $60 \mathrm{~s}, 40^{\circ} \mathrm{C}$ for $30 \mathrm{~s}$ for Rep and Eric and $52{ }^{\circ} \mathrm{C}$ for Box, and $72{ }^{\circ} \mathrm{C}$ for $90 \mathrm{~s}$; following by one cycle at $72{ }^{\circ} \mathrm{C}$ for $10 \mathrm{~min}$. Amplicons were visualized in agarose gel $1.5 \%$. The binary matrix obtained by the principle of presence and absence of bands with the same molecular size was used to generate a neighbor-joining grouping with 1000 bootstrap replication by PAUP software version 4.0b10 (Swofford, 2002).

\section{Results}

Aerobic and/or anaerobic bacterial growth resulted from the conjunctival surface of 36 out of 40 eyes (90\%). On the other hand, aerobic and/or anaerobic bacterial growth was obtained from aqueous humor samples of only patients 1, 3 and 4 (15\%). Patients 1 and 3 did not show bacterial growth in the presurgical samples, while all the three patients presented bacterial growth of aqueous humor samples from both eyes after surgery. Thus, conjunctival surface and aqueous humor samples from dogs 1, 3 and 4 were submitted to bacterial isolation.

After BOX-PCR analysis, 24 isolates with different profiles (Fig. 1) had their 16S rRNA region sequenced (accession numbers in the NCBI GenBank KP994634-KP994657). These isolates were identified as Enterobacter spp., Staphylococcus spp., S. aureus, Pantoea spp. and Streptococcus spp. (Fig. 2). The identification of bacterial genus corresponding to each genetic profile allowed the identification of the remaining isolates (Table 1 ). Isolates supposed to be $S$. aureus were submitted to specific PCR (Sasaki et al., 2010) for species confirmation.

Thus, from the total of isolates obtained, Enterobacter spp., Staphylococcus spp. and $S$. aureus were identified in conjunctival surface samples in the proportion of $61.5 \%, 28.2 \%$ and $10.3 \%$, respectively. From aqueous humor samples, $43.9 \%$ of isolates belonged to Enterobacter spp., $34.1 \%$ to Pantoea spp., $17.1 \%$ to Streptococcus spp. and $4.9 \%$ to Staphylococcus spp. Isolates of Streptococcus spp. were identified only in samples of aqueous humor collected from patient 4 before surgery. Additionally, bacterial cultures from conjunctival surface and aqueous humor samples, collected after surgery, were submitted to PCR with species-specific primers for Streptococcus spp. (Meiri-Bendek et al., 2002) and none of the samples showed to be positive, which corroborates the results obtained by bacterial isolation and sequencing.

The sequenced isolates and others selected by BOX-PCR were submitted to the complete rep-PCR analysis, being 39 isolates from the conjunctival surface samples and, 7 and 34 isolates from aqueous humor samples collected before and after surgery, respectively. The 80 isolates selected were separated into five different groups by rep-PCR with high genetic diversity (Fig. 3). In general, the isolates were separated into subgroups according to dogs and sources, conjunctival and aqueous humor, from which they were obtained, showing its relative genetic specificity. As exception, isolates HLA1.3 to HLA1.6 from patient 1 showed to be genetically closely similar to isolates CR3.1 to CR3.7 and CL3.16 from patient 3, which leads to the assumption that they are from the same origin.

Only Enterobacter spp. genus was found in both aqueous humor and conjunctival surface samples from dogs 1 and 4. In the molecular tree obtained by rep-PCR analysis, we observed some Enterobacter spp. isolates that may be related to cross infection. Isolates CR4.1, CR4.2 and CR4.5 from conjunctival surface samples were genetically closely similar to HRA4.4, HRA4.5, HRA4.7, HLA4.1, HLA4.2 and HLA4.6 from aqueous humor samples of patient 4 . In the same way, CR4.9 showed genetic similarity with HRA4.2 (Fig. 3). Thus, out of 24 Enterobacter spp. isolates obtained from conjunctival surface, $16.6 \%$ were genetically related to those from aqueous humor samples.

Thereby, the results indicated that contamination of anterior chamber during phacoemulsification may come from a variety of sources besides conjunctival surface. All patients were followed up for one year after surgery. Only patient 3 developed postoperative endophthalmitis that was successfully treated with antibiotics. Even after contamination of the anterior chamber, the dogs 1 and 4 did not develop endophthalmitis.

\section{Discussion}

Some of the bacterial strains and genus identified in aqueous humor samples were not present in those from conjunctival surface, which leads us to point out not only the microbiota from conjunctival surface as source of contamination, but also additional sources.

Bacterial growth has been reported in conjunctival surface in $65 \%$ of cases in humans (Leong et al., 2002) and $81.8 \%$ in dogs (Ledbetter et al., 2004). The microorganisms of conjunctival flora are abundant in both humans and dogs and, due to this fact, there is a high risk of cross infection during surgery. The literature has also already reported bacterial growth in aqueous humor samples of dogs submitted to cataract surgery (Taylor et al., 1995; Ledbetter et al., 2004; Johnstone and Ward, 2005). A study reported 5\% of bacterial isolates from conjunctival flora to be similar to those found in the aqueous humor samples by biochemical analysis (Ledbetter et al., 2004). In the present 
study, $10.2 \%$ of isolates from conjunctival surface were genetically related to those from aqueous humor samples. In other studies, contamination of anterior chamber in humans were reported in $1.8 \%$ (Baillif et al., 2012) to 5\% (Samad et al., 1995) of the cases.

The most common microorganisms identified in dogs' conjunctiva are gram-positive bacteria, although the gram-negative ones have also been isolated (Prado et al., 2005). The prevalence of $S$. aureus, S. intermedius, S. epidermidis, Bacillus sp., Proteus mirabilis and Enterobacter cloacae in the conjunctival sac of healthy dogs had been reported (Andrade et al., 2002). In turn, Staphylococcus spp., S. aureus, Streptococcus spp., Pseudomonas aeruginosa and Enterobacter spp. were associated to ulcerative keratitis (Gerding and Kakoma, 1990; Sueke et al., 2010). Staphylococcus spp. belongs to the bacterial flora of conjunctival surface of dogs and is considered the most abundant genus in clinically healthy dogs (Gerding and Kakoma, 1990; Andrade et al., 2002). Even though the resident flora plays an important role in the host defense mechanism by preventing the colonization of opportunistic pathogens (McClellan, 1997), in a previous study it has been related to $82 \%$ of intraocular infections and, in this context, coagulase-negative staphylococci have been associated to $50 \%$ of acute postoperative endophthalmitis (Mistlberger et al., 1997). Conjunctival flora is the main source of bacterial contamination of the anterior chamber (Ariyasu et al., 1993) and contaminates the aqueous humor in up to $30 \%$ of the cases (Auclin et al., 2001).

Enterobacter spp. was the most prevalent genus encountered in conjunctival surface samples of this study and, as previously reported, this bacterial genus can be associated to keratitis cases (Sueke et al., 2010). According to the genetic diversity analysis based on rep-PCR markers, Enterobacter spp. strains present in the conjunctival surface of the patient 4 was found in aqueous humor samples, probably owing to a cross infection. In the literature, contamination of anterior chamber after phacoemulsification in dogs by bacterial strains similar to those present in conjunctival surface was reported for the species Staphylococcus epidermidis (Samad et al., 1995), Pantoea agglomerans and Bacillus sp. (Ledbetter et al., 2004).

Some Enterobacter spp. strains, Staphylococcus spp. strains, Pantoea spp. and Streptococcus spp. genus present in aqueous humor samples and not found in conjunctival surface may have contaminated the anterior chamber during the surgery. In addition to conjunctival flora, the microbiota present in the eyelid margins and ocular surface of eyes is a considerable cause of postoperative bacterial endophthalmitis (Andrade et al., 2002).

By the aid of molecular markers, bacterial strains can usually be related to their hosts (Agostinho et al., 2014). This was observed in our work with some exceptions that could be indicative of contamination from surgical supplies and environment. Other sources of contamination are represented by the IOLs. These lenses have affinity to dirt particles and can be contaminated merely by exposure to the surgery room air (Vafidis et al., 1984). Furthermore, extraocular fluids, disposable materials and surgical instruments directly in contact to the anterior chamber are also contamination sources (Taylor et al., 1995).

Even though three dogs showed the presence of viable potential pathogenic bacteria in their anterior chamber at the end of surgery, none of the eyes developed untreatable infectious endophthalmitis. Antimicrobial therapy applied during and after surgical procedures has played an essential role in preventing infection. Also, when faced with contamination, the defense mechanisms of the eye, such as immunoglobulins present in the aqueous humor and phagocytes of the trabecular meshwork endothelium, are mobilized (Ledbetter et al., 2004). Streptococcus spp. genus was identified in aqueous humor samples only before surgery. In this case, it is possible that fluid exchange during irrigation/aspiration at the time of surgery has been responsible for the mechanical clearing of microorganisms from the anterior chamber (Shimada et al., 2017). The antimicrobial properties of the aqueous humor also contribute to decrease the risks of contamination (Mistlberger et al., 1997).
The sequencing of $16 \mathrm{~S}$ rRNA region and genetic diversity analysis by molecular markers of bacterial isolates from dogs' eyes confirmed the association of the reported bacterial genus to conjunctival surface and the possibility of its cross infection with aqueous humor. The significant genetic diversity of bacterial isolates reported from aqueous humor samples in our study is suggesting that a variety of sources may be responsible for contamination during surgery.

Therefore, in order to avoid postoperative endophthalmitis, the use of preoperative, intraoperative and postoperative broad-spectrum antibiotics is important to limit the effect of anterior chamber contamination from conjunctiva, other periocular structures or the surgical environment.

\section{Ethics statement}

This research was conducted following the guidelines of the Association for Research in Vision and Ophthalmology - ARVO (National Institutes of Health Publications No 85-23: Revised 1985) and approved by the Animal Ethics Commission of the São Paulo State University-FCAV/UNESP, Jaboticabal, São Paulo, Brazil, under protocol number 014628/12.

\section{Acknowledgments}

The authors would like to thank financial supports of Brazil, the São Paulo Research Foundation (FAPESP 2011/18641-7), Coordination for the Improvement of Higher Level -or Education- Personnel (CAPES) and the National Counsel of Technological and Scientific Development (CNPq 300833/2010-5) for their support.

\section{Appendix A. Supplementary data}

Supplementary data associated with this article can be found, in the online version, at https://doi.org/10.1016/j.vetmic.2017.11.028.

\section{References}

Agostinho, J.M.A., Souza, A., Schocken-Iturrino, R.P., Beraldo, L.G., Borges, C.A., Ávila, F.A., Marin, J.M., 2014. Escherichia coli strains isolated from the uteri horn, mouth, and rectum of bitches suffering from pyometra: virulence factors, antimicrobial susceptibilities, and clonal relationships among strains. Int. J. Microbiol. 1-8.

Andrade, A.L., Stringhini, G., Bonello, F.L., Marinho, M., Perri, S.H.V., 2002. Conjunctival microbiota of healthy dogs in Araçatuba city (SP). Arq. Bras. Oftalmol. 65, 323-326.

Ariyasu, R.G., Nakamura, T., Trousdale, M.D., Smith, R.E., 1993. Intraoperative bacterial contamination of the aqueous humor. Ophthalmic. Surg. 24, 367-374.

Auclin, F., Pollet, E., Roman, S., Boureau-Andrieux, C., Leroux-Les-Jardins, S., Ullern, M., 2001. Fifty-two cases of postoperative endophthalmitis treated with one protocol: anatomical and functional results. J. F. Ophtalmol. 24, 687-691.

Bag, S., Saha, B., Mehta, O., Anbumani, D., Kumar, N., Dayal, M., Pant, A., Kumar, P., Saxena, S., Allin, K.H., Hansen, T., Arumugam, M., Vestergaard, H., Pedersen, O., Pereira, V., Abraham, P., Tripathi, R., Wadhwa, N., Bhatnagar, S., Prakash, V.G., Radha, V., Anjana, R.M., Mohan, V., Takeda, K., Kurakawa, T., Nair, G.B., Das, B., 2016. An improved method for high quality metagenomics DNA extraction from human and environmental samples. Sci. Rep. 6. http://dx.doi.org/10.1038/ srep26775.

Baillif, S., Roure-Sobas, C., Le-Duff, F., Kodjikian, L., 2012. Aqueous humor contamination during phacoemulsification in a university teaching hospital. J. Fr. Ophtalmol. 35, 153-156.

Edgar, R.C., 2004. MUSCLE: multiple sequence alignment with high accuracy and high throughput. Nucleic Acids Res. 32, 1792-1797.

Ewing, B., Green, P., 1998. Basecalling of automated sequencer traces using phred. II. Error probabilities. Genome Res. 8, 186-194.

Gerding Jr., P.A., Kakoma, I., 1990. Microbiology of the canine and feline eye. Vet. Clin. North Am. Small Anim. Pract. 20, 615-625.

Gilger, B.C., 1997. Phacoemulsification. Technology and fundamentals. Vet. Clin. North Am. Small Anim. Pract. 27, 1131-1141.

Gordon, D., Abajian, C., Green, P., 1998. Consed: a graphical tool for sequence finishing. Genome Res. 8, 195-202.

Green, P., 1996. PHRAD Documentation [dataset]. http://bozeman.mbt.washington. edu/phrap.docs/phrap.html.

Johnstone, N., Ward, D.A., 2005. The incidence of posterior capsule disruption during phacoemulsification and associated postoperative complication rates in dogs: 244 eyes (1995-2002). Vet. Ophthalmol. 8, 47-50.

Koeuth, T., Versalovic, J., Lupski, J.R., 1995. Differential subsequence conservation of 
interspersed repetitive Streptococcus pneumoniae BOX elements in diverse bacteria. Genome Res. 5, 408-418.

Ledbetter, E.C., Millichamp, N.J., Dziezyc, J., 2004. Microbial contamination of the anterior chamber during cataract phacoemulsification and intraocular lens implantation in dogs. Vet. Ophthalmol. 7, 327-334.

Leong, J.K., Shah, R., McCluskey, P.J., Benn, R.A., Taylor, R.F., 2002. Bacterial contamination of the anterior chamber during phacoemulsification cataract surgery. J. Cataract Refract. Surg. 28, 826-833.

Li, H.B., Singh, R.K., Singh, P., Song, Q.Q., Xing, Y.X., Yang, L.T., Li, Y.R., 2017. Genetic diversity of nitrogen-fixing and plant growth promoting Pseudomonas species isolated from sugarcane rhizosphere. Front. Microbiol. 8, 1268.

McClellan, K.A., 1997. Mucosal defense of the outer eye. Surv.Ophthalmol. 42, 233-246.

Meiri-Bendek, I., Lipkin, E., Friedmann, A., Leitner, G., Saran, A., Friedman, S., Kashi, Y., 2002. A PCR-based method for the detection of Streptococcus agalactiae in milk. J. Dairy Sci. 85, 1717-1723.

Mistlberger, A., Ruckhofer, J., Raithel, E., Müller, M., Alzner, E., Egger, S.F., Grabner, G., 1997. Anterior chamber contamination during cataract surgery with intraocular lens implantation. J. Cataract Refract. Surg. 23, 1064-1069.

Mizrahi-Man, O., Davenport, E.R., Gilad, Y., 2013. Taxonomic classification of bacterial 16S rRNA genes using short sequencing reads: evaluation of effective study designs. PLoS One 8, 1-14.

Nercessian, O., Fouquet, Y., Pierre, C., Prieur, D., Jeanthon, C., 2005. Diversity of Bacteria and Archaea associated with a carbonate-rich metalliferous sediment sample from the Rainbow vent field on the Mid-Atlantic Ridge. Environ. Microbiol. 7, 698-714.

Posada, D., Buckley, T.R., 2004. Model selection and model averaging in phylogenetics: advantages of Akaike Information Criterion and bayesian approaches over likelihood ratio tests. Syst. Biol. 53, 793-808.

Prado, M.R., Rocha, M.F., Brito, E.H., Girão, M.D., Monteiro, A.J., Teixeira, M.F., Sidrim, J.J., 2005. Survey of bacterial microorganisms in the conjunctival sac of clinically normal dogs and dogs with ulcerative keratitis in Fortaleza, Ceará, Brazil. et. Ophthalmol. 8, 33-37.
Ronquist, F., Huelsenbeck, J.P., 2003. MrBayes 3: Bayesian phylogenetic inference under mixed models. Bioinformatics 19, 1572-1574.

Samad, A., Solomon, L.D., Miller, M.A., Mendelson, J., 1995. Anterior chamber contamination after uncomplicated phacoemulsification and intraocular lens implantation. Am. J. Ophthalmol. 120, 143-150.

Sasaki, T., Tsubakishita, S., Tanaka, Y., Sakusabe, A., Ohtsuka, M., Hirotaki, S., Kawakami, T., Fukata, T., Hiramatsu, K., 2010. Multiplex-PCR method for species identification of coagulase-Positive staphylococci. J. Clin. Microbiol. 48, 765-769.

Sharma, S., 2012. Diagnosis of infectious diseases of the eye. Eye (Lond). 26, 177-184.

Sherwood, D.R., Rich, W.J., Jacob, J.S., Hart, R.J., Fairchild, Y.L., 1989. Bacterial contamination of intraocular and extraocular fluids during extracapsular cataract extraction. Eye (Lond). 3, 308-312.

Shimada, H., Arai, S., Nakashizuka, H., Hattori, T., Yuzawa, M., 2017. Reduced anterior chamber contamination by frequent surface irrigation with diluted iodine solutions during cataract surgery. Acta Ophthalmol. 95, 373-378.

Srinivasan, R., Karaoz, U., Volegova, M., MacKichan, J., Kato-Maeda, M., Miller, S., Nadarajan, R., Brodie, E.L., Lynch, S.V., 2015. Use of 16S rRNA gene for identification of a broad range of clinically relevant bacterial pathogens. PLoS One 10, 1-22.

Sueke, H., Kaye, S., Neal, T., Murphy, C., Hall, A., Whittaker, D., Tuft, S., Parry, C., 2010. Minimum inhibitory concentrations of standard and novel antimicrobials for isolates from bacterial keratitis. Invest. Ophthalmol. Vis. Sci 51, 2519-2524.

Swofford, D.L., 2002. PAUP*: Phylogenetic analysis using parsimony (* and other methods) 4.0b10. Sinauer Associates, Sunderland, Mass.

Taylor, M.M., Kern, T.J., Riis, R.C., McDonough, P.L., Erb, H.N., 1995. Intraocular bacterial contamination during cataract surgery in dogs. J. Am. Vet. Med. Assoc. 206 1716-1720.

Vafidis, G.C., Marsh, R.J., Stacey, A.R., 1984. Bacterial contamination of intraocular lens surgery. Br. J. Ophthalmol. 68, 520-523.

Versalovic, J., Schneider, G.M., Frans, J., De Bruijn, F.J., Lupski, J.R., 1994. Genomic fingerprinting of bacteria using repetitive sequence-based polymerase chain reaction. Methods Mol. Cell. Biol. 5, 24-40. 